\title{
Haemophilus Influenzae Type B Impairment of Pial Vessel Autoregulation in Rats
}

\author{
IVOR D. BERKOWITZ, WILLIAM R. HAYDEN, RICHARD J. TRAYSTMAN, \\ AND M. DOUGLAS JONES, JR. \\ Department of Anesthesiology/Critical Care Medicine and Pediatrics, The Johns Hopkins Medical Institutions, \\ Baltimore, Maryland 21287
}

\begin{abstract}
To examine the mechanisms of autoregulatory impairment in meningitis, we studied the effects of Haemophilus influenzae type b (Hib) on pial vessels during hemorrhagic hypotension in rats, using a cranial window technique. We prepared cranial windows in barbiturateanesthetized, mechanically ventilated rats. Artificial cerebrospinal fluid or $10^{5}$ Hib in cerebrospinal fluid $(n=7$ each group) was suffused over the pial surface. Pial arteriolar diameter was measured hourly for $4 \mathrm{~h}$. Autoregulation was assessed as the ability of pial arterioles to dilate in response to graded hemorrhagic hypotension at 2 and 4 h. Pial arterioles exposed to Hib dilated progressively to $149 \pm 27 \%$ of baseline at $4 \mathrm{~h}$. Vessel diameter in the Hib group was significantly greater than in the control group beginning at $2 \mathrm{~h}$. Autoregulation was progressively impaired in Hib-exposed rats compared with control rats $[-5.85 \pm 1.38$ versus $-8.02 \pm 2.02$ and $-3.82 \pm 1.57$ versus $-8.53 \pm 1.72 \%$ dilation $/ \mathbf{k P a}$ fall in mean arterial blood pressure at 2 and $4 \mathrm{~h}$, respectively $(p<0.05)]$. These data suggest that autoregulation is impaired in pial arterioles exposed to Hib because involved vessels have a finite dilatory capacity and are close to maximal dilation before hypotensive challenge. (Pediatr Res 33: 48-51, 1993)
\end{abstract}

\section{Abbreviations}

Hib, Haemophilus influenzae type b

$\mathrm{CSF}$, cerebrospinal fluid

Altered cerebral autoregulation characterizes the cerebrovascular bed of humans (1) and and animals (2) with acute bacterial meningitis. Such impairment could contribute to the high incidence of neurologic morbidity and the high mortality rate of this disease $(3,4)$ by decreasing cerebral blood flow under circumstances of only a modest reduction of cerebral perfusion pressure. Mechanisms of autoregulatory impairment are, however, unknown.

Blood vessels coursing over the brain surface are likely to be particularly vulnerable to the effects of bacteria and inflammation. Therefore, to examine the roles of both cortical microcirculatory dilation and vasoparesis in the autoregulatory impairment of meningitis, we studied the effects of Hib on pial vessels during hemorrhagic hypotension in rats, using a cranial window technique.

Received July 30, 1991; accepted September 2, 1992.

Correspondence and reprint requests to: Ivor D. Berkowitz, M.D., Department of Anesthesiology/Critical Care Medicine, The Johns Hopkins Hospital, $600 \mathrm{~N}$. Wolfe Street, Halsted 842, Baltimore, MD 21287.

Supported by USPHS NIH Grant NS 20020.

\section{MATERIALS AND METHODS}

Animal preparation. The protocol for this study was approved by the Animal Care and Use Committee of the Johns Hopkins Medical Institutions. Male Wistar rats weighing 250-300 g (Harlan Sprague Dawley, Indianapolis, IN) were anesthetized with thiopental $75 \mathrm{mg} / \mathrm{kg}$ administered intraperitoneally. Supplemental doses of thiopental $(10 \mathrm{mg} / \mathrm{kg})$ were administered during and after surgery to deepen light planes of anesthesia manifest by increasing blood pressure to $>16.7 \mathrm{kPa}$. A tracheostomy was performed, and the animals were ventilated with a Harvard rodent ventilator. Respiratory rate, fractional inspired $\mathrm{O}_{2}$ concentration, and tidal volume were adjusted to obtain desired arterial blood gases. Rectal temperature was maintained at $38^{\circ} \mathrm{C}$ with a servo-controlled heating pad. A femoral artery and vein were cannulated to measure blood pressure, obtain blood samples, administer drugs and fluid, and induce hemorrhagic hypotension by blood withdrawal. The animals were then paralyzed with i.v. pancuronium, $0.1 \mathrm{mg} / \mathrm{kg}$.

Cranial window. Cranial windows were constructed with modifications of the technique described by Morii et al. (5). After the cranium was secured in a stereotactic frame, the skull was exposed by excising skin, fascia, and periosteum from forehead to occiput. Hemostasis was achieved with ferric-chloride-soaked cotton pledgets. The residual ferric chloride was then thoroughly removed with normal saline irrigation. Two lengths of polyethylene tubing (PE90) for perfusion of artificial CSF and measurement of intracranial pressure were passed through drilled holes in a $7-\mathrm{mm}$ diameter, $1.5-\mathrm{mm}$-thick plastic ring cut from the barrel of a 5-mL plastic syringe. The ring was then cemented to the skull over the parietal bone with dental acrylic. A craniotomy to remove an approximately $3-\times 4-\mathrm{mm}$ segment of parietal bone, within the area enclosed by the ring, was performed under a microscope with an air-cooled dental drill. After the bone flap was removed, the underlying dura and arachnoid were incised with a 27 -gauge needle and removed with microforceps. Hemostasis was obtained by crushing the vessels at the free edge of the dura with microforceps. Artificial CSF fluid (5) $\left(\mathrm{Na}^{+} 156.5\right.$ $\mathrm{mmol} / \mathrm{L}, \mathrm{K}^{+} 2.95 \mathrm{mmol} / \mathrm{L}, \mathrm{Ca}^{2+} 2.50 \mathrm{mmol} / \mathrm{L}, \mathrm{Mg}^{2+} 1.33$ $\mathrm{mmol} / \mathrm{L}, \mathrm{Cl}^{-} 138.7 \mathrm{mmol} / \mathrm{L}, \mathrm{HCO}_{3}^{-} 24.6 \mathrm{mmol} / \mathrm{L}$, dextrose $3.69 \mathrm{mmol} / \mathrm{L}$, and urea $6.69 \mathrm{mmol} / \mathrm{L}$ ) was aerated with $5 \% \mathrm{CO}_{2}$ in air at $38^{\circ} \mathrm{C}$ and filled the window. A glass coverslip was placed over the plastic ring, and air bubbles were removed. The window was then sealed with additional dental acrylic, and $3 \mathrm{~mL}$ of artificial CSF was superfused through the window. After a 30min stabilization period, the intracranial pressure was set at 5 $\mathrm{cm} \mathrm{H}_{2} \mathrm{O}$ by adjusting the height of the exit catheter.

Microscope and video systems. Pial vessels were observed using an Olympus binocular microscope (model BHMJ, Olympus Corp., Lake Success, NY). The window was illuminated by a high-intensity illuminator equipped with a flexible fiberoptic light source (Fiber-Lite series 108, Dolan-Jenner Industries, Inc., Woburn, MA). A video camera (Ikegami television camera 
model ITC-140, type T, Ikegami Tsushinki Co., Ltd., Japan) attached to the microscope produced an image displayed on a high-resolution monitor (Panasonic Color Video Data Monitor, CT-1400MG, Panasonic Industrial Co., Secaucus, NJ). This image was recorded on a video cassette recorder (Panasonic model NV-8950). Magnification with this system was $145 \times$ and $415 \times$ using $2.5 \times$ and $10 \times$ objective lenses, and fields of view on the video monitor were $1775 \times 2390 \mu \mathrm{m}$ and $620 \times 835 \mu \mathrm{m}$, respectively. Measurements of selective pial vessels were made directly from the video monitor screen with callipers.

Bacterial inoculum. Hib strain Eagan was stored in skim milk at $-70^{\circ} \mathrm{C}$. Before use, the organism was subcultured on chocolate agar, then grown for $3 \mathrm{~h}$ in fastidious MIC broth supplemented with fastidious organism supplement (Becton Dickinson Diagnostic Instrument Systems, Towson, MD). The broth was diluted with artificial CSF to a turbidity that yielded a colony count of $10^{4}-10^{5}$ organisms $/ \mathrm{mL}$. Control CSF perfusate consisted of the broth culture medium diluted $10^{4}$ times in artificial CSF, a concentration of culture medium similar to that of the bacterial suspension.

Experimental protocol. After $30 \mathrm{~min}$ of stabilization, measurements were made (time $0 \mathrm{~h}$ ); then $3 \mathrm{~mL}$ of either control CSF (control group) or bacterial suspension (Hib group), aerated with $5 \% \mathrm{CO}_{2}$ in air, were perfused through the window. Hourly measurements of temperature and mean blood pressure and a 20 -s video recording of the selected pial vessels were made. A field that contained a segment of arteriole and several venules was selected, and subsequent recordings were made of the same field.

At 2 and $4 \mathrm{~h}$, graded hemorrhagic hypotension was produced by withdrawal of blood from the arterial catheter into a heparinized syringe. Blood pressure was decreased in random order to levels of $80,60,50$, and $40 \%$ of baseline blood pressure, and video recordings were made after stabilization for 2 min at each blood pressure. Blood was reinfused after each hypotensive episode to restore blood pressure to baseline for $2 \mathrm{~min}$, and the procedure was then repeated. Autoregulation index is expressed as the percentage of dilation $/ \mathrm{kPa}$ reduction in mean arterial blood pressure. Measurements of hematocrit and arterial blood gases were made at time 0,2 , and $4 \mathrm{~h}$. Seven rats were studied in each experimental group.

Statistical analysis. Data were analyzed with two-way analysis of variance with repeated measures over time. Mean values were compared by the Duncan new multiple-range test. Statistical significance was set at $p<0.05$. Values are presented as means $\pm \mathrm{SD}$.

\section{RESULTS}

Arterial blood gases, hematocrit, and mean arterial blood pressure were monitored throughout these experiments and were comparable in control and Hib groups at 0,2 , and $4 \mathrm{~h}$ (Table 1).
Pial arterioles ranging in diameter from 19 to $33 \mu \mathrm{m}$ were studied. There was no difference in mean pial arteriolar diameter at $0 \mathrm{~h}$ between control and Hib groups $(23 \pm 3$ and $25 \pm 5 \mu \mathrm{m})$, respectively. Control animals exhibited no time-related changes in pial arteriolar diameter. In contrast, pial arterioles exposed to Hib dilated progressively. Diameter was significantly greater after $2 \mathrm{~h}$ of exposure to Hib than in the control group and was $149 \pm$ $27 \%$ of the baseline diameter after $4 \mathrm{~h}$ (Fig. 1).

The response of pial arterioles to graded hemorrhagic hypotension was assessed at 2 and $4 \mathrm{~h}$ in the same control and Hibexposed groups (Fig. 2). Vessel diameters are expressed as the percentage of baseline diameter at time 0 . Hypotensive control animals showed marked pial arteriolar vasodilation with vessels dilating from $104 \pm 6$ to $177 \pm 21 \%$ at $2 \mathrm{~h}(p<0.05)$ and from $104 \pm 6$ to $181 \pm 21 \%$ at $4 \mathrm{~h}(p<0.05)$ (Fig. 2). Arterioles in the Hib group, however, were more dilated than vessels in the control group at normotension at both 2 and $4 \mathrm{~h}$ (Fig. 2) but dilated to similar diameters (176 \pm 15 and $181 \pm 25 \%$ at 2 and $4 \mathrm{~h}$, respectively) as vessels in the control group at equivalent levels of maximum hypotension. Blood pressure at maximum induced hypotension was $5.73 \pm 0.67$ and $6.17 \pm 0.67 \mathrm{kPa}$ in the $\mathrm{Hib}$ group and the control group, respectively, at $2 \mathrm{~h}$ and $6.13 \pm 0.93$ and $5.87 \pm 0.67 \mathrm{kPa}$ in these groups at $4 \mathrm{~h}$.

Visual inspection shows that the relationship between the percentage of dilation and mean arterial pressure is approximately linear (Fig. 2). Linear regression analysis was performed separately on data from each animal. The regression coefficients were averaged, yielding for each group of measurements on "autoregulatory index," defined as the percentage dilation $/ \mathrm{kPa}$ fall in mean arterial blood pressure. Indexes for each time period are given in Figure 3. The index for the Hib group was significantly less than control at both 2 and $4 \mathrm{~h}$. In addition, autoregulation deteriorates over time in the Hib group, as evidenced by an autoregulatory index that was significantly less at $4 \mathrm{~h}$ than at $2 \mathrm{~h}$.

Pial venules studied in each rat were divided into small and large venules ranging in diameter from 19 to 29 and 33 to 107 $\mu \mathrm{m}$, respectively. There was no statistical difference in pial venular diameter of either size category between control and Hib groups for $4 \mathrm{~h}$ at normotension (Table 2).

\section{DISCUSSION}

Over the past decade, dramatic advances have been made in unravelling the complexities of the molecular pathophysiology of inflammation in bacterial meningitis (6). Specific bacterial components that incite meningeal inflammation have been defined, and the role of amplifiers of the meningeal inflammatory cascade such as complement, platelet-activating factor, cytokines, and prostanoids have been investigated (6). Nevertheless, the specific pathophysiologic events responsible for CNS damage remain unclear. Alterations in cerebral blood flow, either reduced

Table 1. Arterial blood gases, hematocrit, and mean arterial blood pressure

\begin{tabular}{|c|c|c|c|c|c|c|}
\hline & Group* & $0 \mathrm{~h}$ & $1 \mathrm{~h}$ & $2 \mathrm{~h}$ & $3 \mathrm{~h}$ & $4 \mathrm{~h}$ \\
\hline \multirow[t]{2}{*}{ Hematocrit } & I & $44 \pm 4$ & & $43 \pm 4$ & & $40 \pm 7$ \\
\hline & II & $41 \pm 4$ & & $45 \pm 7$ & & $45 \pm 5$ \\
\hline $\mathrm{PaO}_{2} \dagger(\mathrm{kPa})$ & I & $17.6 \pm 4.5$ & & $18 \pm 3.7$ & & $18.1 \pm 3.2$ \\
\hline \multirow[t]{2}{*}{$\mathrm{PaCO}_{2} \ddagger(\mathrm{kPa})$} & $\mathrm{I}$ & $5.1 \pm 0.5$ & & $5.1 \pm 0.5$ & & $5.1 \pm 0.4$ \\
\hline & II & $5.3 \pm 0.4$ & & $4.9 \pm 0.5$ & & $4.7 \pm 0.4$ \\
\hline $\mathrm{pH}$ & I & $7.39 \pm 0.02$ & & $7.39 \pm 0.03$ & & $7.37 \pm 0.03$ \\
\hline $\begin{array}{l}\text { Mean arterial blood pres- } \\
\text { sure }(\mathrm{kPa})\end{array}$ & II & $16.1 \pm 1.1$ & $15.7 \pm 0.9$ & $15.7 \pm 0.9$ & $15.1 \pm 0.9$ & $15.5 \pm 0.9$ \\
\hline
\end{tabular}

* Group I, control group; group II, Hib group.

$+\mathrm{PaO}_{2}$, arterial $\mathrm{O}_{2}$ tension.

$\ddagger \mathrm{PaCO}_{2}$, arterial $\mathrm{CO}_{2}$ tension. 


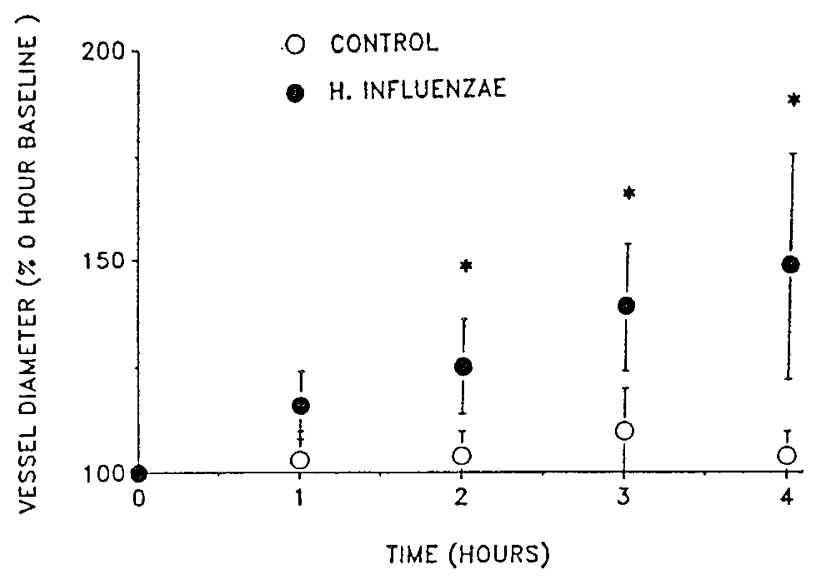

Fig. 1. Pial arteriolar diameters measured over $4 \mathrm{~h}$ in control and Hib-exposed rats ( $n=7$ in each group). Values are expressed as the percentage of 0 -h baseline diameter. Asterisks denote values significantly different from control group measurements.
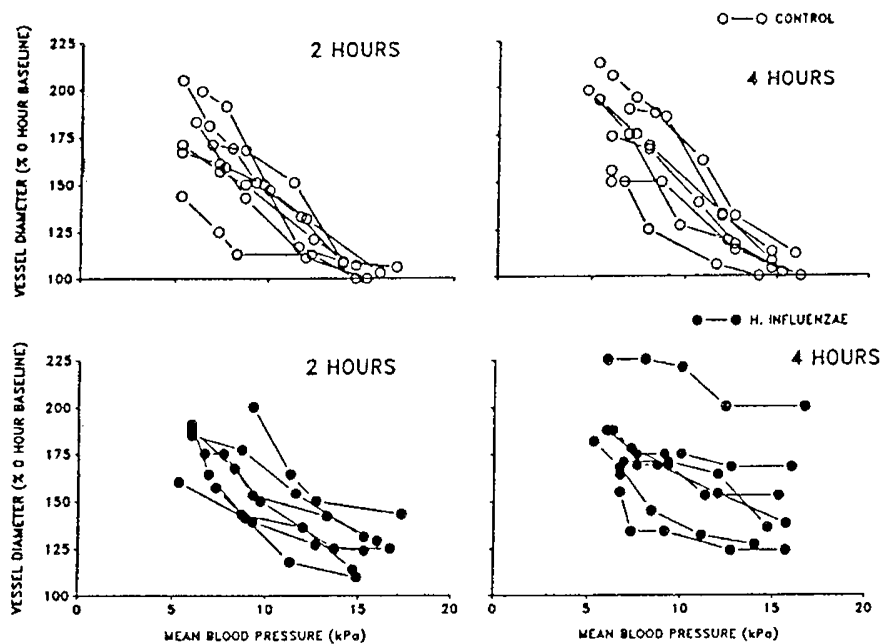

Fig. 2. Pial arteriolar diameters in response to hemorrhagic hypotension at 2 and $4 \mathrm{~h}$ in individual control and Hib-exposed rats $(n=7$ in each group). Values are expressed as the percentage of 0 -h baseline diameter.

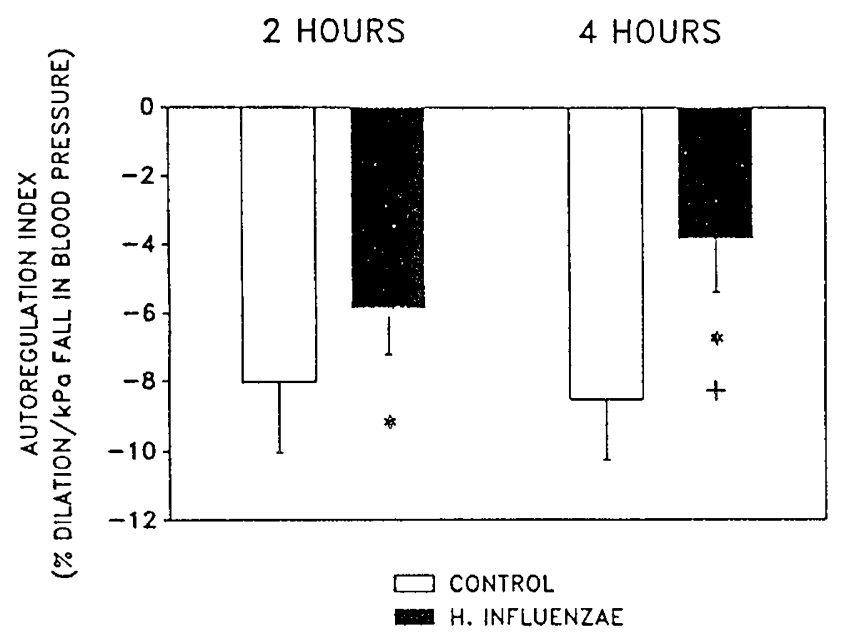

Fig. 3. Autoregulation index in control and $\mathrm{Hib}$ groups. Autoregulation index $=\%$ dilation $/ \mathrm{kPa}$ fall in mean arterial blood pressure. ${ }^{*} \mathrm{p}<$ 0.05 vs control group at same time; $+p<0.05$ vs 2-h value of same group. blood flow with ischemia (7) or hyperemia with increased cerebral blood volume that might increase intracranial pressure (2), could contribute to CNS damage.

We demonstrated several major findings in this study of the effects of Hib on pial vasculature. First, pial exposure to Hib, at concentrations present in clinical meningitis, produces marked arteriolar vasodilation. Second, exposure to bacteria impairs pial arteriolar autoregulation.

Pial arteriolar vasodilation develops rapidly after bacterial exposure. At $2 \mathrm{~h}$, vasodilation is significantly greater than in the control group of animals. Such vascular congestion has been observed at autopsy in cases of human (8) and animal meningitis (9). Although some studies have suggested that cerebral blood flow in meningitis is reduced, Pfister et al. (10), using laserDoppler flowmetry, demonstrated increased regional cerebral blood flow within $1 \mathrm{~h}$ of inducing pneumococcal meningitis in rats. The almost $50 \%$ pial arteriolar vasodilation observed at $4 \mathrm{~h}$ in our study implies approximately a 5-fold increase in pial arteriolar blood flow because of the 4th power relationship between vessel diameter and flow and supports the suggestion of cerebral hyperemia in the acute phase of bacterial meningitis (10). An important advantage of the pial window technique for examining cerebral vasculature in meningitis is that it permits direct examination of the pial circulation exposed to bacteria without the possible interference from either dural circulation (as in laser-Doppler flowmetry studies) (10) or the complicating effects of generalized elevated intracranial pressure that develops in other meningitis models. Vasodilation in this meningitis model could be attributed to CSF acidosis; inflammatory mediators such as vasoactive prostaglandins, e.g. prostaglandin $\mathrm{E}_{2}(11$, 12); cytokines, e.g. tumor necrosis factor and IL (11); or oxygenderived free radicals $(10,13)$.

Autoregulation, expressed as the autoregulation index-the means of the slopes of the autoregulatory plots for each experiment-is impaired in the Hib group compared with the control group. In addition, the impairment of autoregulation is time dependent with progressive reduction from 2 to $4 \mathrm{~h}$. The mechanisms of autoregulatory impairment in infected animals are unknown, but our data suggest that blunting of the autoregulatory response in the $\mathrm{Hib}$ group is explained by physical constraints placed upon the pial arteriolar vasculature by vasodilation. Assuming that pial arterioles have a finite dilatory capacity (14) of approximately $180 \%$, pial arterioles in the infected group that have dilated to $149 \%$ of 0 -h baseline are closer to the vasodilatory limit. This mechanism of impaired autoregulation would be autologous to the blunting of autoregulation observed at cerebral vasodilation with hypercarbia (15) or dihydralazine (16). These agents dilate the cerebral vasculature, increase cerebral blood flow, and impair cerebral autoregulation. Impaired autoregulation may not only reflect a limitation of passive dilation, it may also represent a component of generalized vasoparesis caused by exposure to bacteria that possibly impairs vascular smooth muscle function. Keyes et al. (17) demonstrated such vasoparesis of pial vessels exposed to group B streptococci. These vessels failed to either constrict or dilate further in response to hypocapnia and hypercapnia, respectively. Failure of pial arterioles to vasoconstrict in response to elevated systemic blood pressure would support vasoparalysis as a potential mechanism of impaired autoregulation during hypertension. Vessel response to hypertension was not, however, evaluated in this study. Other investigators have demonstrated loss of autoregulation in bacterial meningitis (2), but global cerebral blood flow was evaluated rather than the pial circulation, in which the brunt of the changes might be expected.

The findings of this experimental study have clinical implications. Impairment of cerebral autoregulation in meningitis places the cerebral circulation at risk of hypoperfusion with cerebral ischemia from even a modest decrease in cerebral perfusion pressure from either hypotension or increased intracranial pressure, both common complications of bacterial meningitis. The 
Table 2. Pial venular diameter (\% 0-h baseline diameter)

\begin{tabular}{|c|c|c|c|c|c|c|}
\hline & Group & $0 \mathrm{~h}$ & $1 \mathrm{~h}$ & $2 \mathrm{~h}$ & $3 \mathrm{~h}$ & $4 \mathrm{~h}$ \\
\hline \multirow[t]{2}{*}{ Small venules* } & I & $100 \pm 0$ & $101 \pm 11$ & $114 \pm 12$ & $121 \pm 15$ & $110 \pm 14$ \\
\hline & II & $100 \pm 0$ & $110 \pm 11$ & $115 \pm 22$ & $116 \pm 28$ & $120 \pm 29$ \\
\hline Large venules $\dagger$ & I & $100 \pm 0$ & $101 \pm 6$ & $99 \pm 9$ & $100 \pm 10$ & $101 \pm 14$ \\
\hline
\end{tabular}

* Mean diameter at $0 \mathrm{~h}(\mu \mathrm{m})$ : group I, $25 \pm 4$; group II, $25 \pm 1$.

$\dagger$ Mean diameter at $0 \mathrm{~h}(\mu \mathrm{m})$ : group I, $45 \pm 18$; group II, $66 \pm 30$.

potential adverse effects of increased cerebral blood volume in meningitis are, however, less well appreciated. Pial arteriolar dilation of approximately $50 \%$ baseline arteriolar diameter, after $4 \mathrm{~h}$ of exposure to $\mathrm{Hib}$, implies more than a doubling of the blood flow of this vascular bed. Despite an approximately $50 \%$ decrease in pressure from aorta to pial arterioles (18), such vasodilation and an increase in blood volume can potentially contribute to the elevated intracranial pressure of bacterial meningitis. Pial window studies of cats receiving systemic dihydralazine indeed demonstrated that pial arteriolar dilation is accompanied by a doubling of intracranial pressure (16).

In summary, we have shown that pial arterioles, but not venules, dilate when exposed to $\mathrm{Hib}$ in a pial window preparation in rats. These arterioles demonstrate an impaired autoregulatory response, possibly because involved vessels that have a finite vasodilatory capacity are close to maximally dilated before the hypotensive challenge.

Acknowledgments. The authors thank Marilyn R. Loeb, Ph.D., for supplying the Hib strain Eagan; Patricia Charache, M.D., for technical assistance; and Linda Wilson and Erika Gaines for their fine secretarial support in preparing this manuscript.

\section{REFERENCES}

1. Paulson OB, Brodersen P, Hensen EL, Kristensen HS 1974 Regional cerebral blood flow, cerebral metabolic rate of oxygen, and cerebrospinal fluid acidbase variables in patients with acute meningitis and acute encephalitis. Acta Med Scand 196:191-198

2. Tureen JH, Dworkin RJ, Kennedy SL, Sachdeva M, Sande MA 1990 Loss of cerebrovascular autoregulation in experimental meningitis in rabbits. $J$ Clin Invest 85:577-581

3. Feigin RD, Stechenberg BW, Chang MJ, Dunkle LM, Wong ML, Palkes H, Dodge PR, Davis H 1976 Prospective evaluation of Hemophilus influenzae meningitis. J Pediatr 88:542-548
4. Sell SHW, Merrill RE, Doyne ED, Zimsky EP 1972 Long term sequelae of Hemophilus influenzae meningitis. Pediatrics 49:206-211

5. Morii S, Ngai AC, Winn HR 1986 Reactivity of rat pial arterioles and venules to adenosine and carbon dioxide: with detailed description of the closed cranial window technique in rats. J Cereb Blood Flow Metab 6:34-41

6. Saez-Llorens X, Ramilo O, Mustafa MM, Mertsola J, McCracken GH 1990 Molecular pathophysiology of bacterial meningitis: current concepts and therapeutic implications. J Pediatr 116:671-684

7. Smith AL, Roberts MC, Haas JE, Stull TL, Mendelman PM 1985 Mechanisms of Haemophilus influenzae type b meningitis. In: Sande MA, Smith AL, Root RK (eds) Bacterial Meningitis. Churchill Livingstone, New York, pp $11-21$

8. Adams RD, Kubik CS, Bonner FJ 1948 The clinical and pathological aspects of influenzae meningitis. Arch Pathol 65:354-376

9. Moxon ER, Smith AL, Averill DR, Smith DH 1974 Hemophilus influenzae meningitis in infant rats after intranasal inoculation. J Infect Dis 129: $154-162$

10. Pfister HW, Koedel U, Haberl RL, Dirnagl U, Feiden W, Ruckdeschel G, Einhaupl KM 1990 Microvascular changes during the early phase of experimental bacterial meningitis. J Cereb Blood Flow Metab 10:914-922

11. Mustafa MM, Ramilo O, Saez-Lllorens X, Olsen KD, Magness RR, McCracken GH 1990 Cerebrospinal fluid prostaglandin, interleukin 1B, and tumor necrosis factor in bacterial meningitis. Am J Dis Child 144:883-887

12. Morii S, Warg R, Ohtaka H, Yada K 1989 The in vitro effect of iloprost, a stable prostacyclin analogue, on the caliber of the cerebral microvessels. $J$ Cereb Blood Flow Metab 9(suppl 1):S666(abstr)

13. McKnight AA, Keyes WG, Hudack ML, Jones Jr MD 1992 Oxygen free radicals and the cerebral arteriolar response to Group B streptococci. Pediatr Res 31:640-644

14. Tuor UI, Farrar JK 1984 Pial vessel caliber and cerebral blood flow during hemorrhagic and hypercapnia in the rabbit. Am J Physiol 247:H40-H5

15. Raichle ME, Stone HL 1972 Cerebral blood flow autoregulation and graded hypercapnia. Eur Neurol 6:1-5

16. Johansson BB, Auer LM, Trummer UG 1980 Pial vascular reaction to intravenous dihydralazine in the cat. Stroke 11:369-371

17. Keyes WG, Hudak ML, Jones MD 1988 Effect of group B streptococci (GBS) on meningeal vessels. Pediatr Res 23:474A(abstr)

18. Harper SL, Bohlen HG, Rubin MJ 1984 Arterial and microvascular contributions to cerebral cortical autoregulation in rats. Am J Physiol 246: $\mathrm{H} 17-\mathrm{H} 24$ 